NOTICE: this is the author's version of a work that was accepted for publication in Technological Forecasting and Social Change. Changes resulting from the publishing process, such as peer review, editing, corrections, structural formatting, and other quality control mechanisms may not be reflected in this document. Changes may have been made to this work since it was submitted for publication. A definitive version was subsequently published in Technological Forecasting and Social Change, Vol. 79, Issue 3, March 2012 http://dx.doi.org/10.1016/j.techfore.2011.09.004 


\title{
World Natural Gas Endowment as a Bridge towards Zero Carbon Emissions
}

\author{
Roberto F. Aguilera ${ }^{\mathrm{a}}$, Roberto Aguilera ${ }^{\mathrm{b}}$
}

\begin{abstract}
We use a global energy market (GEM) model to show that natural gas has the potential to help stabilize global carbon emissions in a span of about 50-100 years and pave the way towards low and zero carbon energy.

The GEM provides a close fit of the global energy mix between 1850 and 2005. It also matches historical carbon and $\mathrm{CO} 2$ emissions generated by the combustion of fossil fuels. The model is used then to forecast the future energy mix, as well as the carbon and $\mathrm{CO} 2$ emissions, up to the year 2150 .

Historical data show relative decarbonization and an increase in the amount of hydrogen burned as a percent of fossil fuel use between 1850 and 1970. The GEM indicates that with a larger contribution of natural gas to the future energy market, the burned hydrogen percentage will increase. This decarbonization will help to advance economic and environmental sustainability.
\end{abstract}

Keywords: Natural gas; Energy Mix; Emissions; Decarbonization

\section{INTRODUCTION}

Energy services are a vital need and are indispensable for human well-being. Significant challenges exist, ranging from energy security to environmental quality. Historically, economic growth has been primarily fuelled by coal and oil. As the world economy

\footnotetext{
${ }^{a}$ Corresponding Author. Curtin University, Centre for Research in Energy and Minerals Economics (CREME), GPO Box 1987, Perth, Australia, 6845. Email: r.aguilera@ curtin.edu.au, Phone: 618-9266-9137

${ }^{\mathrm{b}}$ University of Calgary, Chemical and Petroleum Engineering Department, 2500 University Drive NW, Calgary, Canada, T2N-1N4. Email: r.aguilera@ucalgary.ca
} 
continues to expand over the long term, natural gas has the potential to play a significant role in satisfying energy demand and acting as a bridge towards renewables (1). Increased use of gas will help to reduce dependency on oil and coal, which may result in increased energy security and reduced environmental impact. Thus, the aim of this paper is to analyze the role of natural gas, on a global scale, in providing a sustainable global energy future. In particular, this paper provides projections related to natural gas and its association to the energy mix, decarbonization, and carbon emissions.

The themes of this paper support the work of experts visualizing a bright future for natural gas as a transition fuel (e.g. 1-7). Common forecasting models for estimated energy demand include IEA MARKAL (8) and the IAEA MAED (9). For a comparative study of energy demand models, see (10). Reserve estimates are presented annually in the British Petroleum Statistical Review of World Energy (11) and by the U.S. Energy Information Administration (12). Estimates of resources are periodically assessed by the United States Geological Survey (13) and the German BGR (14).

Recent natural gas estimates indicate marketable resources of 2,074 tcf in the United States (15), and 700 to 1,300 tcf in Canada (16), are much larger than previously assessed. The same holds true for the world when natural gas in conventional, tight, shale and coalbed reservoirs is taken into account (17-18). 
The endowment in these four types of reservoirs is estimated at 45,000 trillion cubic feet (tcf) split into 15,000 tcf in conventional reservoirs; 15,000 in tight gas reservoirs; 10,000 in shale gas reservoirs; and 5,000 in coalbed reservoirs. ${ }^{1}$

Endowment refers to the sum of known volumes of hydrocarbons (cumulative production plus remaining reserves) and undiscovered volumes (13). We estimate that cumulative gas production for the world until 2005 is approximately 2,776 tcf. Thus, the 'future endowment' (i.e. endowment minus cumulative production) suggests that at current rates of natural gas production of $106 \mathrm{tcf} /$ year (11), the resource would last for 398 years.

Table 1 presents a summary of alternative conventional and unconventional fossil endowments and the time they would last depending on various assumed production growth rates.

\section{Table 1 - Life expectancies}

\begin{tabular}{|c|c|c|c|c|c|c|}
\hline 1 & 2 & 3 & & 4 & & 5 \\
\hline \multirow[t]{2}{*}{ Commodity } & \multirow[t]{2}{*}{$\begin{array}{l}\text { Future }^{\text {a }} \\
\text { Volumes }\end{array}$} & \multirow{2}{*}{$\begin{array}{c}2007-2009^{b} \\
\text { Average Annual } \\
\text { Production }\end{array}$} & \multicolumn{3}{|c|}{$\begin{array}{l}\text { Life Expectancy in Years, at Various } \\
\text { Growth Rates in Production }\end{array}$} & \multirow{2}{*}{$\begin{array}{c}\text { Average Annual } \\
\text { Growth in Production } \\
1979-2009(\%)\end{array}$} \\
\hline & & & $0 \%$ & $2 \%$ & $5 \%$ & \\
\hline Conventional Gas, Tight Gas, Shale Gas, Coalbed & $4.22 \mathrm{E}+16$ & $1.06 \mathrm{E}+14$ & 398 & 110 & 61 & 2.51 \\
\hline Conventional Oil & $3.50 \mathrm{E}+12$ & $2.96 \mathrm{E}+10$ & 118 & 61 & 39 & 0.67 \\
\hline Heavy Oil, Oil Sands, Oil Shale & $2.30 \mathrm{E}+13$ & $2.96 \mathrm{E}+10$ & 777 & 140 & 74 & - \\
\hline
\end{tabular}

Notes:

a. Conventional oil, heavy oil, oil sands and oil shale in barrels; conventional gas, tight gas, shale gas and coalbed in cubic feet

b. Average annual production comes from British Petroleum (2010)

c. Life expectancies estimated by this study

d. Average annual growth in production calculated from British Petroleum (2010)

\footnotetext{
${ }^{1}$ GFREE research team, Schulich School of Engineering, University of Calgary, Canada. GFREE is a target-oriented research program developed in attempts to increase natural gas rates and recoveries from low permeability formations. The program uses an integrated approach that includes geoscience $(\mathrm{G})$, formation evaluation $(F)$, reservoir drilling, completion and stimulation $(R)$, reservoir engineering $(R E)$, and economics and externalities (EE).
} 
In addition to more comfort and convenience, the large gas endowment can help pave the way towards environmental sustainability. As we demonstrate, natural gas use could help stabilize carbon and $\mathrm{CO} 2$ emissions within 50 to 100 years and eventually lead to a zero carbon energy economy in which renewables dominate the energy mix.

\section{THE GLOBAL ENERGY MARKET (GEM) MODEL}

The GEM model is based on a previous logistic substitution model that provided a good match of the energy mix from approximately 1850 to 1970 (19-20). After 1970, the actual historical data deviated from the logistic model. The GEM model takes this deviation into account while providing a good fit of all the historical data.

Figure 1 shows world primary energy consumption and substitution starting in the year 1850. The black curves correspond to actual historical data taken from (21). The color symbols represent the best fit using theoretical values calculated with the GEM model, which is based on a binary technology substitution model given by (19-20):

$$
\frac{f}{1-f}=\exp (\alpha t+\beta)
$$

where $f$ is market share of a competitor, $t$ is time, and $\alpha$ and $\beta$ are parameters. Fisher and Pry define $y_{F P}$ as, 


$$
y_{F P}=\frac{f}{1-f}
$$

Equation 1-1 indicates that a semilogarithmic plot of $y_{F P}$ versus time should result in a straight line with a slope equal to $\alpha$ and intercept equal to $\beta$. We modified equation 1-1 when we observed deviations from the straight line for the energy sources discussed in this study. The deviations included slight or severe increases or decreases in $f$. We handle the deviations empirically by incorporating a severity exponent, $S$, and a parameter, $\psi$, in equation 1-1 (22). The modified equation takes the form (23):

$$
y_{A A}=\frac{\exp (\alpha t+\beta)}{\psi+(1-\psi)\left[1-\exp \left(-\frac{y_{F P}}{y_{C O}}\right)\right]^{S}}
$$

where $y_{C O}$ is a constant determined from the match of the historical data and the theoretical energy fraction is given by:

$$
f=\frac{y_{A A}}{1+y_{A A}}
$$




\section{GEM WORLD PRIMARY ENERGY SUBSTITUTION}

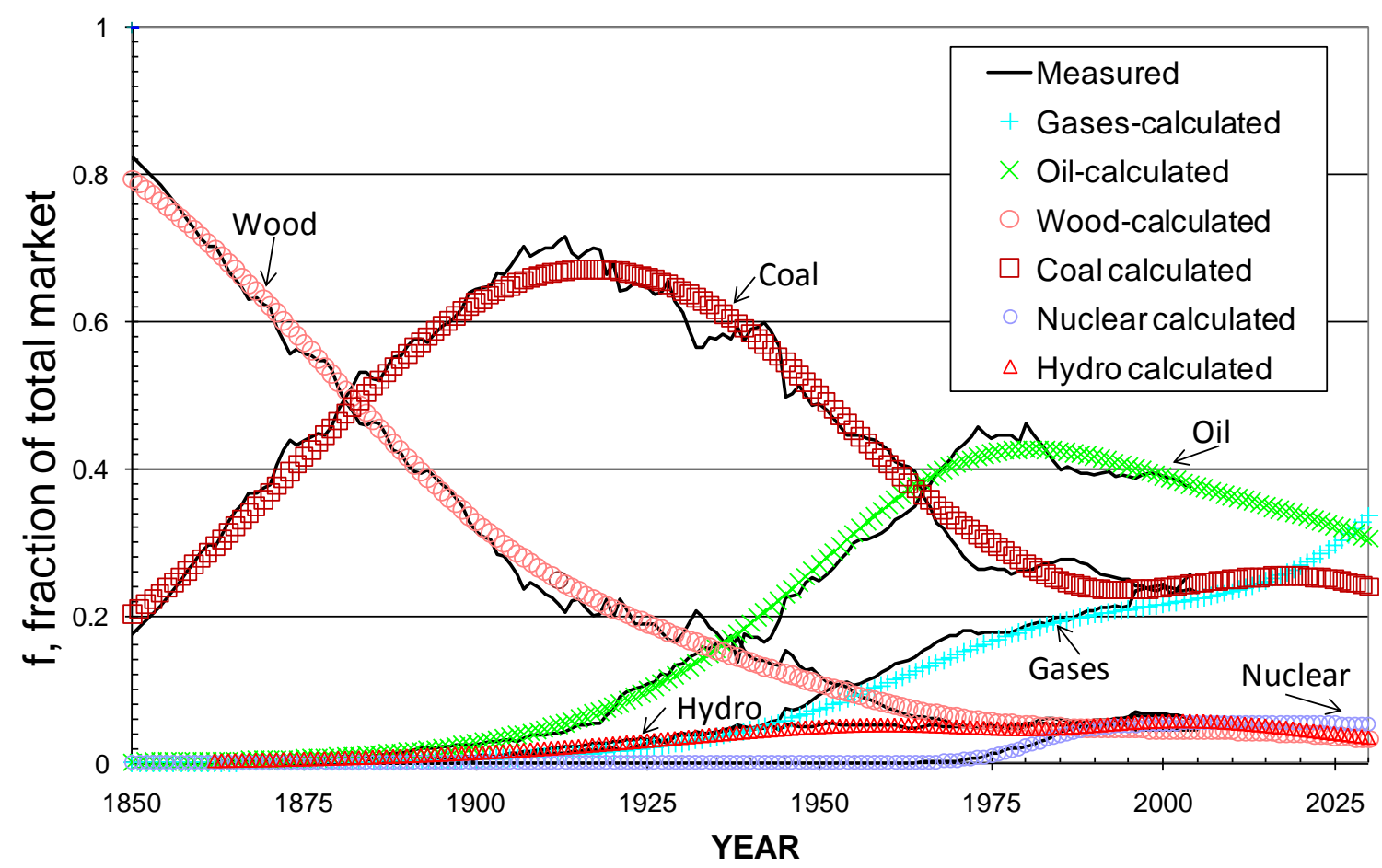

Figure 1 - World substitution curves from the GEM model including wood, coal, nuclear, hydro, oil and gases (23).

As an example, the filled magenta squares in Figure 2 show $[f /(1+f)]$ values of the measured contribution of natural gas to the global energy market versus time. Time zero in the lower horizontal scale corresponds to the year 1850 (shown in the upper horizontal scale). The measured data form an approximate straight line starting in 1906 (56 years in the lower scale) that deviates from linearity around 1968 (118 years in the lower scale). From the straight line, the values of $\alpha$ and $\beta$ are determined to be approximately 0.057 and 8.1, respectively. Other parameters are determined from the trend that deviates from linearity, and are as follows: $\psi=0.052, y_{c o}=3.61$ and $S=1.30$. Finally, the fraction $f$ is calculated from equation 1-4 and is plotted in Figure 2 (shown by the symbol ' $\mathrm{X}$ '). 


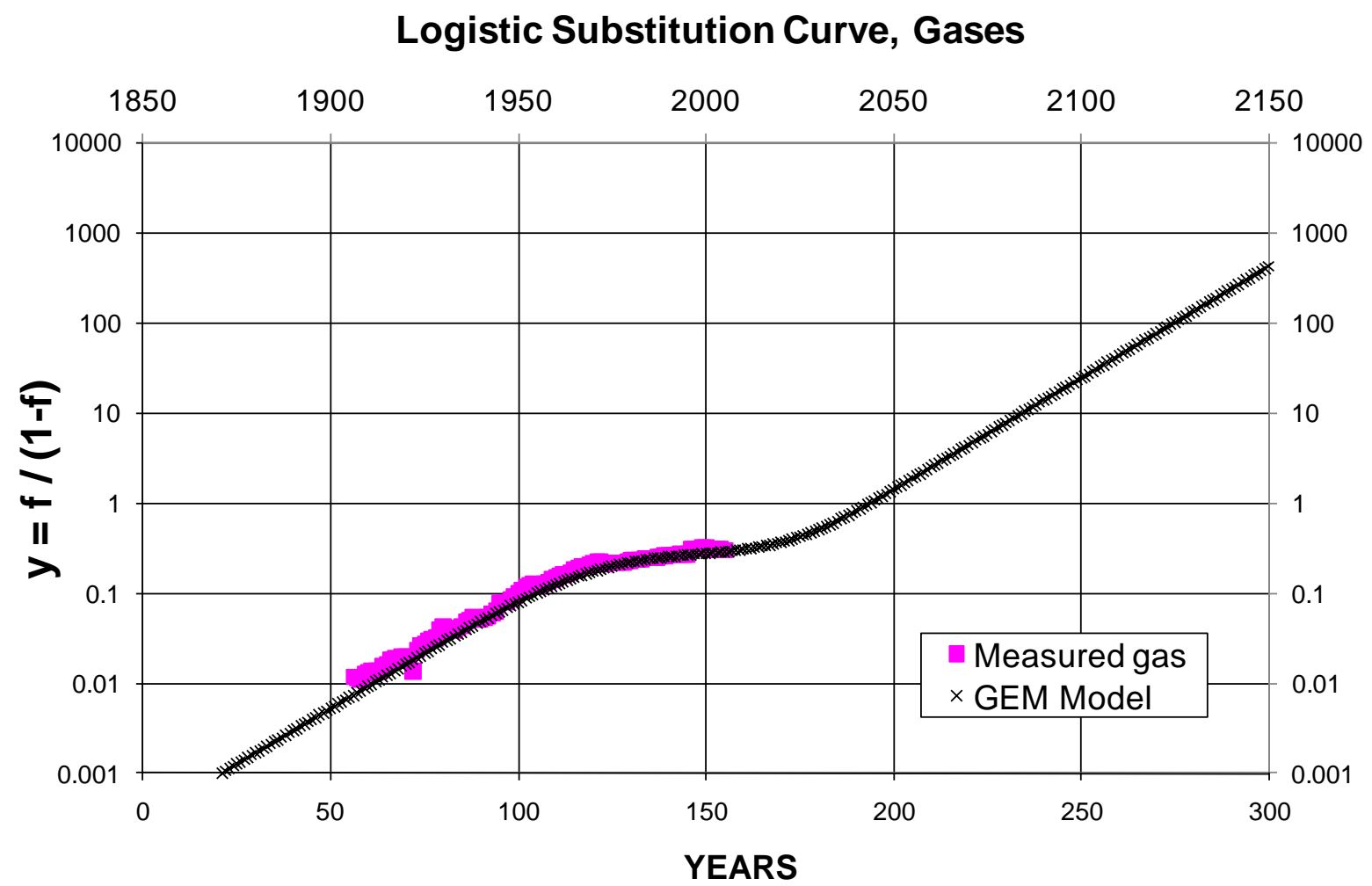

Figure 2 - Use of GEM model for matching historical contribution of natural gas to the global energy market.

\section{RESULTS}

Returning to Figure 1, we see that in 1850, wood, agricultural residues and animal dung contributed approximately $80 \%$ of the total energy market while the share of coal was in the order of $20 \%$. This was followed by a significant increase in coal consumption that reached a peak around 1912, with a contribution of about $70 \%$. At this point, the market share of wood and other solids had decreased to about $22 \%$. 
The oil industry was born in the late $19^{\text {th }}$ century and soon oil was contributing about $7 \%$ of the total energy market. The oil share peaked in the 1970 s with a contribution of about $50 \%$ and would never reach the heights of coal. By that time, the natural gas industry was developing and reached a market share of about $18 \%$. The share of coal had been declining continuously and in the 1970 s stabilized at about $28 \%$. The $4 \%$ balance was composed mostly of hydroelectricity and nuclear energy.

More recently, the contributions of coal and natural gas have been at about $29 \%$ and $24 \%$, respectively, with oil providing approximately $35 \%$ and the balance being contributed by hydroelectricity, nuclear, wind and other minor sources of energy.

Figure 1 also presents a GEM forecast showing that the natural gas share of the global market will continue to increase and reach about $33 \%$ by the year 2030 . On the other hand, the graph also shows that the percent contribution of oil will decrease while that of coal will remain approximately constant. Increased gas penetration in the short term would mostly be found in the electricity sector. In the long term, possibilities may also exist in the transport sector. The increases in gas use could come from policies to address climate change, which are likely to favour gas in place of oil and coal. Some of these policies include indirect taxes on fuel and costs imposed on carbon emissions. By introducing a substantial cost on carbon, for example, the total cost of coal and gas becomes comparable, in which case relative prices determine the dominant fuel. 


\subsection{RELATIVE DECARBONIZATION OF THE ENERGY MARKET}

The significant increases in the endowment of natural gas reported recently (15-18) provide an ideal opportunity to decrease the relative carbon emissions that result from the burning of fossil fuels. This is illustrated in Figure 3, which shows the GEM best fit of the historical hydrogen and carbon burned as a percent of fossil fuel consumption since 1850.

$\% \mathrm{H} 2$ and C OF FOSSIL FUELS BURNED

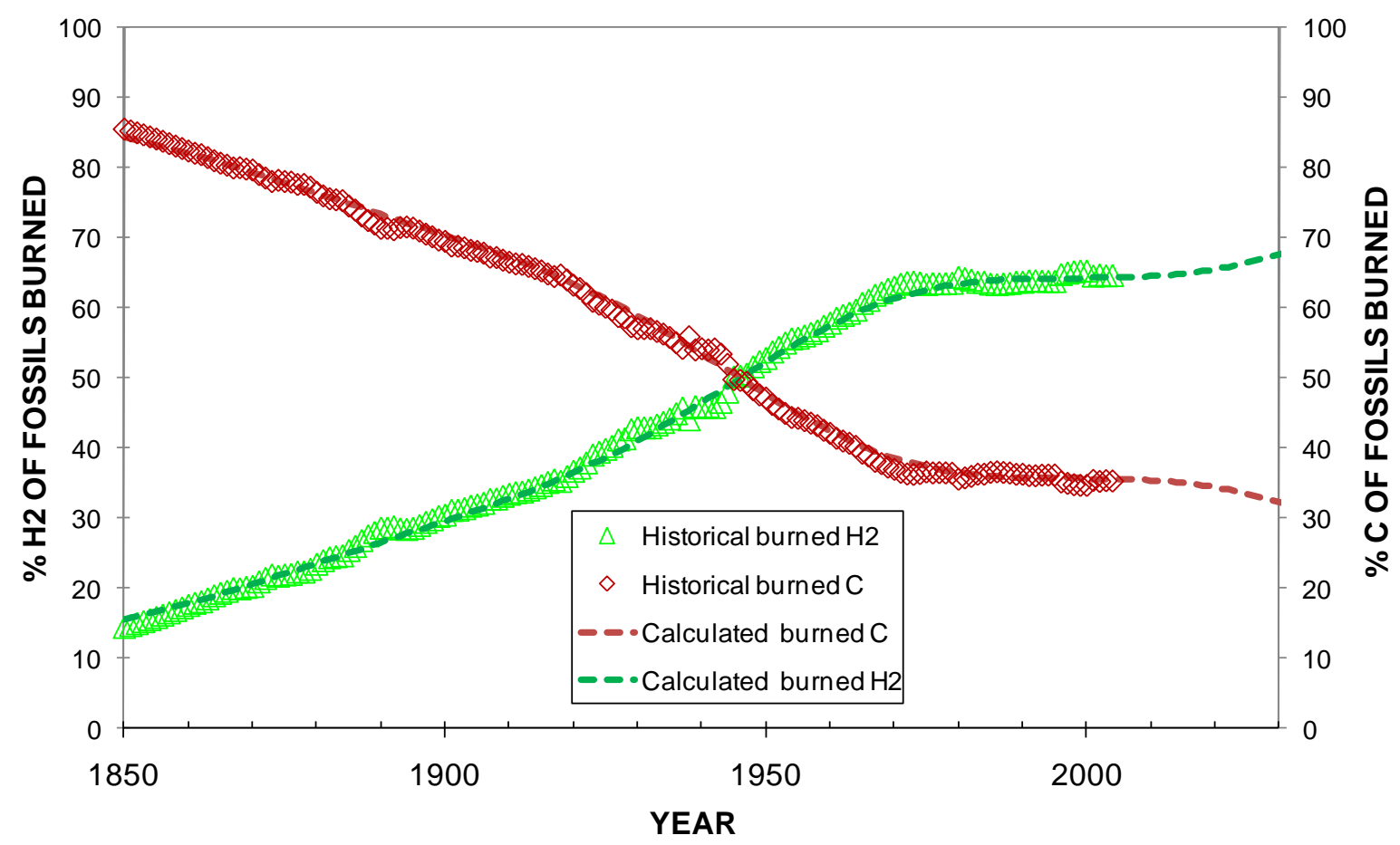

Figure 3 - Percent hydrogen and carbon of fossil fuels burned worldwide.

The calculation of the hydrogen percentage of fossil fuels burned is carried out using the actual (measured) and calculated fractions of wood (including animal dung and other 
agricultural residues), coal, oil and gas shown in Figure 1. Also, the following average $\mathrm{H} / \mathrm{C}$ ratios are used: wood 0.10 , coal 0.5 , oil 2.0 , and gas 4.0 (3). For example, in the year 2004, the percentage of the total market contributed by wood (including animal dung and other agricultural residues) was $4.6 \%$, coal $25.7 \%$, oil $37.5 \%$ and natural gas $23.6 \%$. Thus the overall $\mathrm{H} / \mathrm{C}$ ratio was $0.046 * 0.1+0.257 * .5+0.375 * 2+0.236 * 4=1.827$. The percent of hydrogen burned was $1.827 /(1+1.826)=64.6 \%$. The balance $(35.6 \%)$ represents the carbon burned. The comparison of actual and calculated burned percentages is good, with an $\mathrm{R}^{2}$ equal to 0.99 .

As seen in Figure 3, the percent of burned hydrogen - a proxy for environmental quality has been increasing continuously from $15 \%$ in 1850 to approximately $64 \%$ at present, with the balance of $36 \%$ going to carbon. Beginning in 1970, the hydrogen burned becomes approximately constant at about $64 \%$ and has since remained at the same level. By the year 2030, the burned hydrogen will have increased to approximately $68 \%$, with a corresponding decline in carbon to $32 \%$.

\subsection{ACTUAL CARBONIZATION OF THE ENERGY MARKET}

Although the relative decarbonization illustrated in Figure 3 is important and meaningful, the fact is that actual volumes of carbon emissions to the atmosphere since 1850 have increased substantially, as shown in Figure 4. Thus, in reality there has been an actual carbonization of the global economy, rather than decarbonization. 


\section{The GFREE Low and Zero Carbon Initiative (GEM Model)}

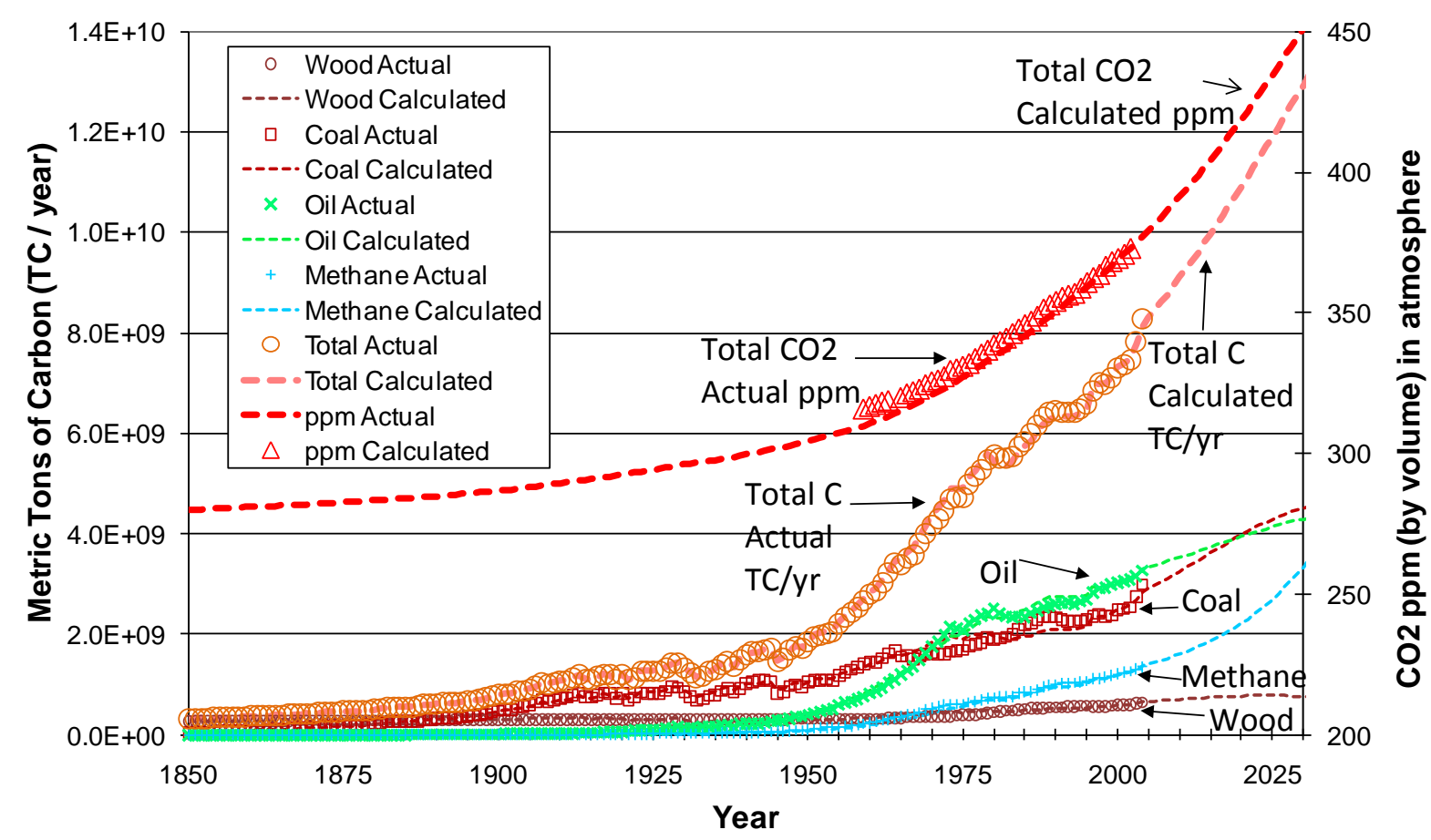

Figure 4 - Actual and best fit global fossil carbon and $\mathrm{CO} 2$ emissions.

The graph in Figure 4 includes individual curves of carbon production from wood (and other solids), coal, oil and natural gas, and the $\mathrm{CO} 2$ equivalent of the total emissions. The dashed curves represent actual data and the color symbols correspond to GEM-calculated carbon and $\mathrm{CO} 2$ values, which fit the actual data very well with coefficients of determination $\left(\mathrm{R}^{2}\right)$ greater than 0.98 in all cases. Figure 4 shows that at present the larger carbon contribution is provided by oil and coal, followed by natural gas (methane). The amount of carbon resulting from burning oil, for example, amounted to 3.27E9 metric tons per year in 2004. The amount is calculated as the product of the fraction of the total 
market contributed by oil (0.375) times total energy consumption (4.19E9 tons of oil equivalent) times the effective fraction oxidized (0.918) times carbon content in tons per ton equivalent of crude oil (0.85). Similar approaches are used for other contributors to the global energy market. Their summation gives the total carbon for 2004, as shown in Figure 4. The curve at the top of the graph $\left(\mathrm{CO}_{2}\right.$ emissions in ppm by volume in the atmosphere) is calculated from the cumulative of the carbon emissions divided the grams of CO2 in a gram of carbon. For example, the cumulative carbon emissions by 2004 were 8.15E9 metric tons. This is converted to grams and divided by 3.664 grams of $\mathrm{CO}_{2}$ per gram of carbon. As the calculation is started in 1850 , we add the estimated $\mathrm{CO}_{2}$ in the atmosphere at that time $(280 \mathrm{ppm})$ to the result of the previous calculation.

As seen in Figure 4, total carbon emissions have increased dramatically since 1950 and at present stand close to about 8.5 billion metric tons of carbon per year. The GEM model forecasts that carbon production will increase to about 13 billion metric tons per year by 2030. This is equivalent to an increase from approximately $384 \mathrm{ppm}$ of CO2 by volume in the atmosphere at present to about $450 \mathrm{ppm}$ of CO2 by volume in 2030. Based on our analysis, the large amounts of carbon can be stabilized within the next 50 to 100 years and eventually be reduced as low and zero carbon energy sources are able to meet the needs of society. 


\subsection{LOW AND ZERO CARBON INITIATIVE}

To accomplish the carbon reductions mentioned above, society would have to take advantage of the vast amounts of available natural gas in conventional, tight, shale and coalbed reservoirs. Using the fit presented in Figure 1, we have generated a production forecast showing the contribution of different sources of energy to the year 2150, as shown in Figure 5.

\section{GEM Forecast, Energy Substitution Curves, Solids, Liquids, Gases}

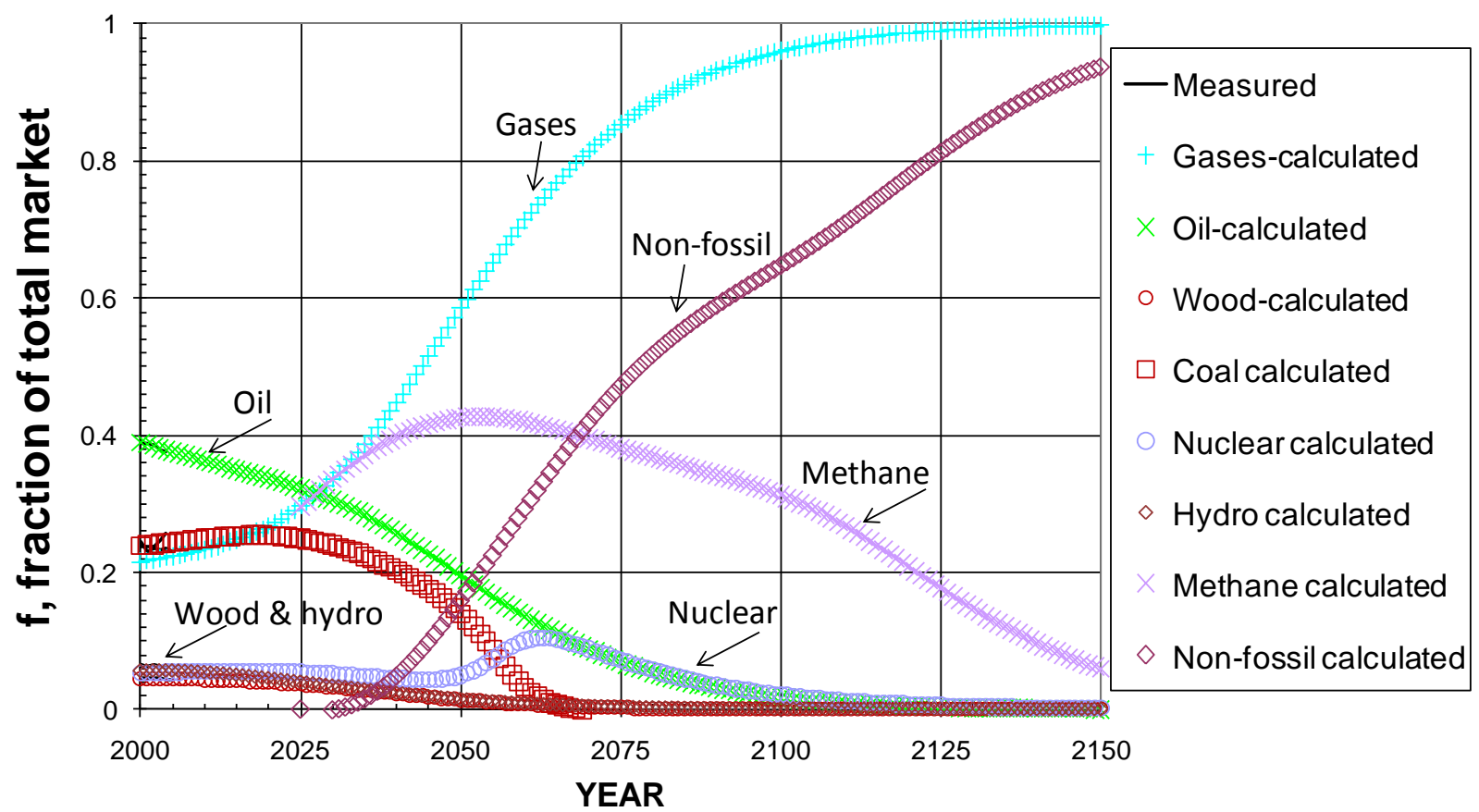

Figure 5 - Forecast substitution curves. Black lines between 2000 and 2010 correspond to the best fit shown in Figure 1. 
This forecast assumes that the fraction of the total market contributed by natural gas will resemble the cycle contributed by oil. The latter started in the late 1800 s and would end in the early 2100 s, not because of lack of oil resources but because of substitution to more environmentally benign sources. A scenario from the GEM model shows that within the next few years the coal share of the energy mix will not increase much more than at present (about 29\%) and will start to decrease significantly and definitively around 2030. As governments force producers to pay for external costs of fossil fuel production, this will increase the relative price of coal while encouraging investment in gas, which would lead to technological improvements in gas exploration, production and transportation. This would further induce substitution from coal towards gas by lowering the relative price of gas.

The natural gas cycle contribution to the total global market would reach a peak around 2050-2060 and then would start to decline, as shown in Figure 5. The availability of natural gas would allow for the necessary time to develop non-fossil, renewable sources.

Figure 6 shows a forecast of carbon emissions from the year 2000 to 2150 . The actual data points starting in the year 2000 are taken from Figure 4. The forecast is performed using the best fit parameters estimated for Figure 4. 


\section{GLOBAL FOSSIL CARBON EMISSIONS The GFREE Low and Zero Carbon Initiative (GEM Model)}

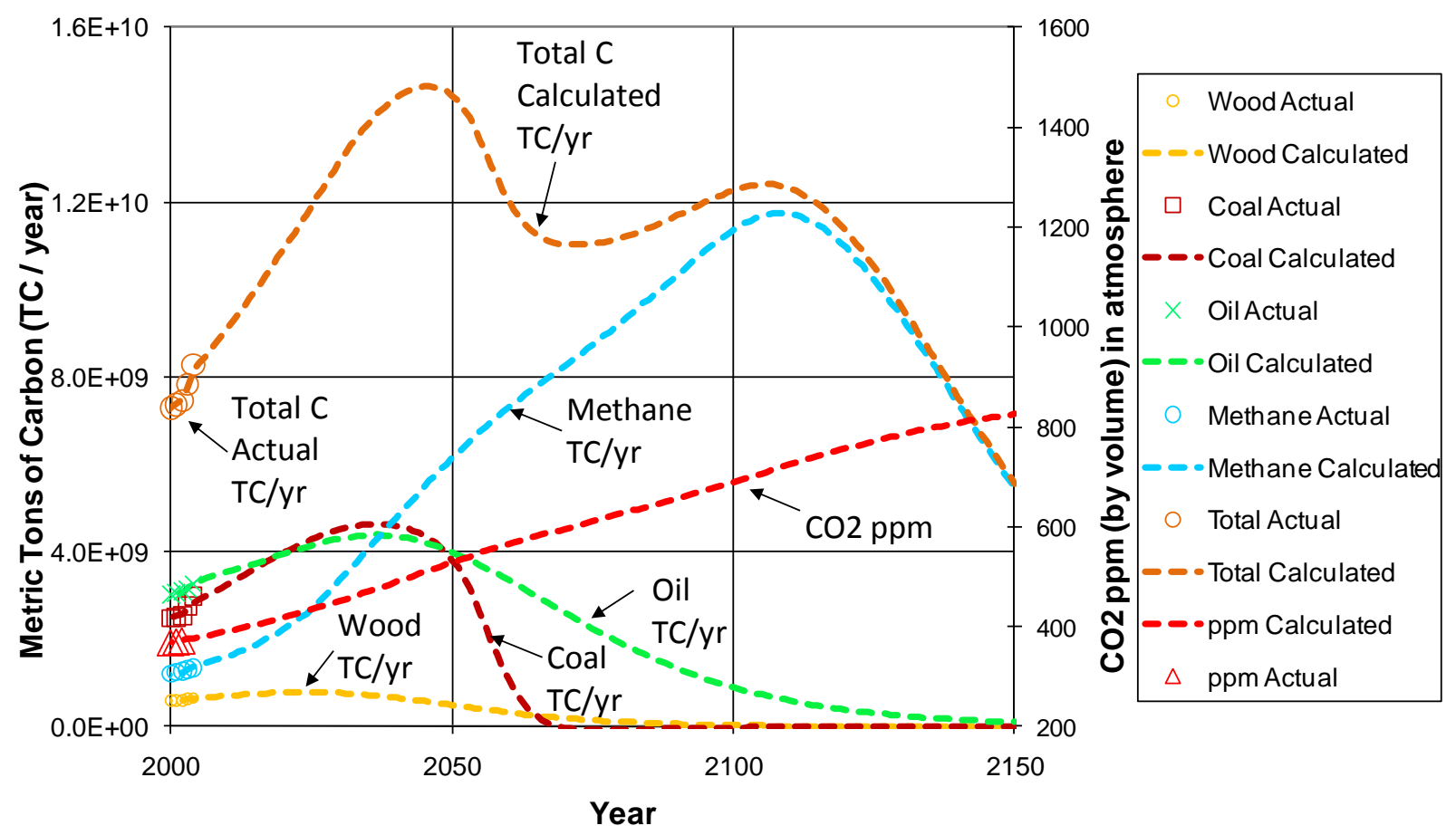

Figure 6 - Forecast of global fossil carbon emissions. The global carbon peak would occur around 2040-2050 with the proposed initiative.

The curves in Figure 6 suggest that carbon contributions by oil and coal would continue to increase and reach a peak around 2040. Just a few years later, the summation of carbon emissions from all sources would reach a maximum. Carbon from natural gas would continue to increase until reaching a peak around 2110.

The overall forecast becomes favorable around 2050 as carbon emissions start to decrease. There is a second peak at a lower level around 2110. That is the point where carbon production per year starts a definitive decline, as seen in Figure 6. 
Notwithstanding that natural gas is the cleanest burning fossil fuel available, it is clear from Figure 7 that natural gas production would generate a significant amount of carbon emissions that would surpass those of oil and coal around 2030 and reach 1E11 metric tons of carbon per year by 2150 . Thus, a transition to non-fossil energy sources, as seen in Figure 5, would be necessary in order to decrease carbon emission levels to those of Figure 6. Possibilities for significant future contributions to the mix would come from a combination of wind, solar, biofuels, water and hydrogen. Hydrogen, an energy carrier, can be generated from natural gas but eventually would have to be produced from nonfossil matter. The possibility of massive and economic generation of hydrogen is being studied by various research teams (24).

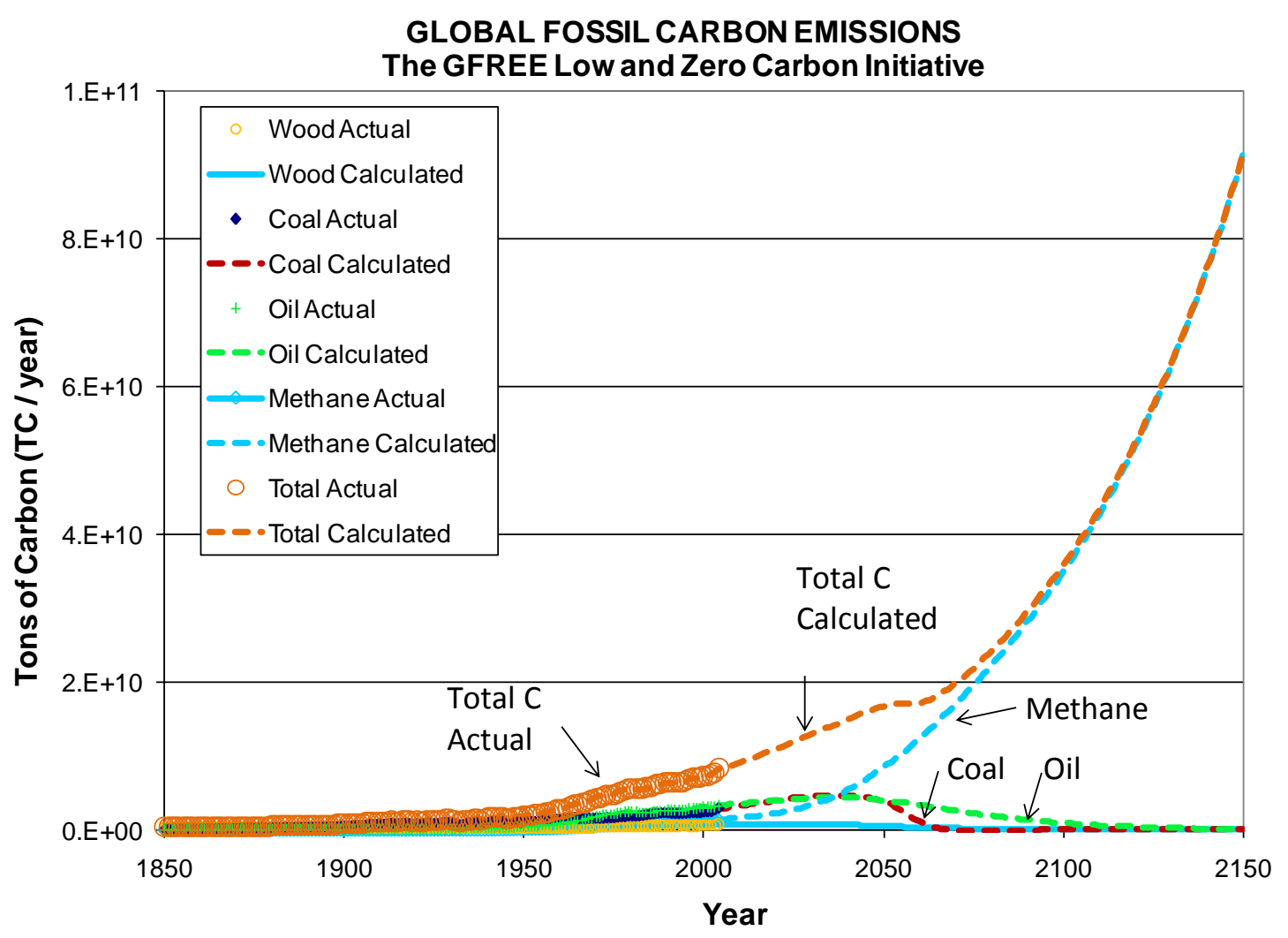

Figure 7 - Even if methane becomes the only source of energy to meet global needs, still the carbon emissions would grow to almost 1E11 metric tons per year by 2150 . 


\section{DISCUSSION}

The GEM projection shown in Figure 1 indicates that the share of natural gas in the future energy mix will increase. However, progress in the natural gas industry will not occur autonomously over time. The effects of energy policy and technology advancement will be critical to develop the large natural gas endowment. Governments must create incentives to produce and deliver abundant conventional and unconventional gas resources to the marketplace. For instance, increases in gas use could come from stringent policies to address climate change, which are likely to favor gas in place of oil and coal. Some of these policies include indirect taxes on fuel and costs imposed on carbon emissions. By introducing a substantial cost on carbon, for example, the total cost of coal and gas becomes comparable, in which case relative prices determine the dominant fuel. Presumably this would increase the relative price of coal while encouraging investment in gas, which would lead to technological improvements in gas exploration, production and transportation. This would further induce substitution from coal towards gas by lowering the relative price of gas.

Similarly, policies will be important in continuing the improvement of the hydrogen over carbon ratio. Figure 3 shows that the percentage of burned hydrogen is likely to increase in 2030 and beyond. However, there must be increased understanding of the actions that encourage or discourage natural gas use. Society may be forced to revert to an intense use of coal if policies are adopted that hinder the penetration of gas into the market place (and thus reduce the percentage of burned hydrogen relative to burned carbon). Government 
regulations such as price setting have the effect of keeping natural gas prices artificially low. These low prices do not provide incentives for companies to invest in the upstream, midstream, or downstream segments of the industry. Increased coal subsidies further hinder the penetration of gas into the market. Policies that limit new entry and foreign investment (either through high taxes and royalties or resource nationalization) will also inhibit the contribution of gas to the energy market.

As seen in Figure 4, total carbon emissions have increased substantially since 1950 and will still be increasing in 2030 due to intensive use of fossil fuels. However, the combination of fossil fuels over the next several decades remains uncertain and will depend heavily on the choices made by governments, corporations and consumers.

Although we have indicated that natural gas is abundant and may allow for the necessary time to develop non-fossil, renewable sources (Figure 5), technical and market research is still needed in the gas and renewables industries. For example, will international gas markets develop sufficiently to stimulate development of shale gas outside the United States and Canada? Will best practice in hydraulic fracturing be achieved around the world to alleviate the fears of associated environmental impacts? Will technology advance enough to reduce the costs of renewable such that they will be cost effective? Questions like these, as well as results from this study, should help inform and drive future research. The carbon emission peak occurring around 2040-2050 (Figure 6) will further depend on the successful development of non-fossil energy sources such as 
hydrogen and renewables. Again, the technical and commercial viability of these sources will require large amounts of investment in research and development.

\section{CONCLUSION}

This study assesses the impacts of competing fuels in the energy mix and finds that natural gas use has the potential to help significantly in the reduction of carbon emissions while increasing economic growth. In addition, increased natural gas use has the potential to fortify regional and international trade relations while ensuring energy security. These themes are important due to the significant global economic and environmental implications.

The GEM model has provided a very good fit of the historical mix of energy sources, including wood (and other solids such as agricultural residues and animal dung), coal, oil, natural gas and other minor sources. The model is also accurate in matching historical carbon and $\mathrm{CO} 2$ emissions generated by the combustion of fossil fuels. These validations provide the basis to make forecasts of the energy mix, and carbon and $\mathrm{CO} 2$ emissions, to the year 2150. Given appropriate energy policy and sufficient technological progress, we find that intensive use of natural gas will help stabilize carbon emissions starting within the next 50 to 100 years. We also anticipate that meeting energy needs with natural gas will allow for the necessary time to develop non-fossil energy sources. As a result, carbon emissions will start to decrease in a definitive way in approximately 100 years. The main 
limitation of the GEM model at present is that its results are contingent on the enactment of policies that encourage the development and consumption of natural gas as well as renewables.

The recent significant additions to the endowment of 'conventional' natural gas in the form of gas from 'unconventional' tight, shale and coalbed reservoirs (and potentially gas hydrate reservoirs) suggest that unconventional gas formations could also provide a significant contribution in meeting global energy demand - estimated at approximately 722 quads by 2030 (23). However, a large unconventional gas endowment does not necessarily imply that gas will capture increased market share in the future and help in the transition towards environmental sustainability. Government regulation has a major role to play in determining the future of unconventional gas. For instance, effective regulation of shale gas production will help mitigate risks such as excessive water use, contamination and disposal.

Additional questions about the long term commercial viability of unconventional fossil fuels and non-fossil alternatives remain unanswered. Thus, future research will include analysis of the total economic cost, including environmental and social costs, of unconventional gas and renewable energy production. The feasibility of renewables, as well as gas as a transition fuel, depends in large part on technological advancement that would lower total production costs over time. Ongoing research into massive and economic generation of hydrogen as an energy source must continue as well. 


\section{ACKNOWLEDGEMENTS}

Parts of this research were funded by the Centre for Research in Energy and Minerals Economics (CREME) at Curtin University in Australia, the Natural Sciences and Engineering Research Council of Canada (NSERC), the Alberta Energy Research Institute (AERI), ConocoPhillips, the Schulich School of Engineering at the University of Calgary and Servipetrol Ltd. Basic data from this research was extracted from the United States Geological Survey (USGS), British Petroleum Statistical Review of World Energy, Energy Information Administration (EIA), International Energy Agency (IEA), and the International Institute for Applied Systems Analysis (IIASA). Their contributions are gratefully acknowledged. 


\section{REFERENCES}

1. International Energy Agency, World Energy Outlook Special Report: Are we Entering a Golden Age of Gas? Paris, France, 2011.

2. J.H. Ausubel, J. H, Can technology Spare the Earth? American Scientist 84 (1996) 166178.

3. A. Grubler, Transitions in Energy Use, Encyclopedia of Energy 6 (2004) 163177.

4. R.A. Hefner III, The Grand Energy Transition, New Jersey, John Wiley and Sons Inc, 2009.

5. A.B. Lovins, B.D. Williams, B. D, A Strategy for the Energy Transition, 10th Annual U.S. Hydrogen Meeting, National Hydrogen Association, Virginia (April 7-9, 1999).

6. C. Marchetti, Nuclear Plants and Nuclear Niches, Nuclear Science Engineering 90 (1985) 521526.

7. V. Vaitheeswaran, Power to the People, New York, Farrar Straus and Giroux, 2005.

8. International Atomic Energy Agency, Model for Analysis of Energy Demand (MAED), Planning and Economic Studies Section, 2006.

9. International Energy Agency, Market Allocation (MARKAL model), Energy Technology Systems Analysis Programme (ETSAP), 2001.

10. S.C. Bhattacharya, G.R. Timilsina, Energy Demand Models for Policy Formulation: A Comparative Study of Energy Demand Models, The World Bank Development Research Group, WPS 4866 (March 2009).

11. British Petroleum, Statistical Review of World Energy, London (2010).

12. Energy Information Administration, World Proved Reserves, U.S. Department of Energy, http://www.eia.gov/international/reserves.html

13. United States Geological Survey, World Petroleum Assessment, Virginia, Unites States (2000).

14. BGR (Federal Institute for Geoscience and Natural Resources), Energy Resources 2009: Reserves, Resources, Availability, Hannover, Germany (2009). 
15. Potential Gas Committee, Assessment of the United States Natural Gas Resources (June 2009).

16. K. Heffernan, F.M. Dawson, An Overview of Canada's Natural Gas Resources. Canadian Society for Unconventional Gas (May 2010).

17. R.F. Aguilera, T. Harding, F. Krause, R. Aguilera, Natural Gas Production from Tight Formations: A Global Perspective, 19th World Petroleum Congress, Madrid, Spain (June 29-July 3, 2008).

18. R. Aguilera, Flow Units: From Conventional to Tight Gas to Shale Gas Reservoirs, Society of Petroleum Engineers SPE paper 132845 (June 27-30, 2010).

19. J.C. Fisher, R.H. Pry, A Simple Solution Model of Technological Change, Report 70_C-215, General Electric Company, Research and Development Center, Schenectady, New York (1970). Referenced by C. Marchetti, Nuclear Plants and Nuclear Niches, Nuclear Science Engineering 90 (1985) 521526.

20. C. Marchetti, N. Nakicenovic, The Dynamics of Energy Systems and the Logistic Substitution Model, International Institute for Applied Systems Analysis (IIASA) Publications RR-79-13, Laxenburg, Austria (1979).

21. A. Grubler, Energy transitions. In: C.J. Cleveland, editor. Encyclopedia of Earth, Washington DC: Environmental Information Coalition, National Council for Science and the Environment, 2008. http://www.iiasa.ac.at/ gruebler/data.htm

22. R.F. Aguilera, Assessing the Long Run Availability of Global Fossil Energy Resources, PhD Dissertation, Colorado School of Mines (2006).

23. R.F. Aguilera, R. Aguilera, Assessing the Past, Present, and Near Future of the Global Energy Market, Society of Petroleum Engineers SPE paper 110215 (November 11-14, 2007).

24. R.F. Aguilera, R. Aguilera, Global Possibilities of Future Methane and Hydrogen Economies, Journal of Petroleum Technology (June 2009) 3439. 


\section{VITAE}

Roberto F. Aguilera is a Research Fellow with the Centre for Research in Energy and Minerals Economics (CREME) at Curtin University, Perth, Australia. Previously, he was a Program Officer and Research Scholar at the International Institute for Applied Systems Analysis (IIASA), an adjunct professor at the University of Vienna, and a Postdoctoral Fellow and Associate Instructor at the Catholic University of Chile. He holds a BComm degree from the University of Calgary as well as MS and PhD degrees in energy economics from the Colorado School of Mines.

Roberto Aguilera, is professor and ConocoPhillips-NSERC-AERI chair in the Schulich School of Engineering, Chemical and Petroleum Engineering Department at the University of Calgary. He is also chairman of the Journal of Canadian Petroleum Technology Editorial Review Board, a principal of Servipetrol, and a director of Junex in Quebec. He is a petroleum engineering graduate from the Universidad de America at Bogotá, Colombia and earned MS and $\mathrm{PhD}$ degrees in petroleum engineering from Colorado School of Mines. He has lectured, presented his course on naturally fractured reservoirs, and done consulting in 50 countries. 